Article

\title{
Synthesis, Characterization and Sensing Properties of AZO and IZO Nanomaterials
}

\author{
Mokhtar Hjiri ${ }^{1}$, Lassaad El Mir ${ }^{1,2}{ }^{*}$ and Salvatore Gianluca Leonardi ${ }^{3}$ \\ 1 Laboratory of Physics of Materials and Nanomaterials Applied at Environment, \\ Faculty of Sciences of Gabes, 6072 Gabes, Tunisia; E-Mail: m.hjiri@yahoo.fr \\ 2 Al Imam Mohammad Ibn Saud Islamic University (IMSIU), College of Sciences, \\ Department of Physics, Riyadh 11623, Saudi Arabia \\ 3 Department of Electronic Engineering, Chemistry and Materials Engineering, \\ University of Messina, 98166 Messina, Italy; E-Mail: leonardis@ unime.it
}

* Author to whom correspondence should be addressed; E-Mail: Lassaad.ElMir@ fsg.rnu.tn; Tel.: +966-531-448-340; Fax: +966-125-81-584.

Received: 24 December 2013; in revised form: 9 April 2014 / Accepted: 13 May 2014 / Published: 23 May 2014

\begin{abstract}
Al-doped $\mathrm{ZnO}$ (AZO) and In-doped $\mathrm{ZnO}$ (IZO) nanopowders were prepared by a sol-gel route and subsequent drying in ethanol under supercritical conditions. The morphological and microstructural properties were investigated by transmission electron microscopy (TEM) analysis and X-ray powder diffraction (XRD). The characterization study showed that the AZO and IZO nanoparticles were crystalline and exhibited the hexagonal wurtzite structure. Chemoresistive devices consisting of a thick layer of synthesized nanoparticles on interdigitated alumina substrates have been fabricated and their electrical and sensing characteristics were investigated. The sensor performances of the AZO and IZO nanoparticles for carbon monoxide (CO) were reported. The results indicated that both doped-sensors exhibited higher response and quick response/recovery dynamics compared to a $\mathrm{ZnO}$-based sensor. These interesting sensing properties were discussed on the basis of the characterization data reported.
\end{abstract}

Keywords: In-doped $\mathrm{ZnO}$; Al-doped $\mathrm{ZnO}$; nanoparticles; sol-gel; gas sensor; $\mathrm{CO}$ 


\section{Introduction}

The development of gas sensors to monitor the toxic and combustible gases is imperative due to the concerns for environmental pollution and the safety requirements for the industry. In general, sensors provide an interface between the electronic equipment and the physical world typically by converting nonelectrical physical or chemical quantities into electrical signals. Recently, gas sensors based on the semiconducting metal-oxides such as $\mathrm{SnO}_{2}$ and $\mathrm{ZnO}$ [1-5] were found to be very useful for detecting the toxic gases. The fundamental sensing principle relies on the change of conductivity of the sensors when they are exposed to certain target gases at moderate temperatures.

The concept of gas sensors using $\mathrm{ZnO}$ thin films was first proposed by Seiyama et al. [6]. $\mathrm{ZnO}$ is sensitive to many gases of interest like hydrocarbons [4], $\mathrm{H}_{2}$ [7], oxygen [8,9], $\mathrm{H}_{2} \mathrm{O}$ [10], $\mathrm{CO}$ [11], $\mathrm{NO}_{2}$ [12], etc., and has satisfactory stability. Moreover, it is robust, has a rapid response with a possibility of miniaturization. However, it has some drawbacks, as high working temperature, normally between 400 and $500{ }^{\circ} \mathrm{C}$, poor gas selectivity and comparatively low gas sensitivity [13].

The most popular strategies employed to enhance sensor performance are the control of material morphology in order to increase the effective area of adsorption and the use of additives which act as a catalyzer of the solid-gas reaction, by a chemical or electronic mechanism, thus promoting the improvement of the sensors properties [14].

Recent reports shown that some dopant species, such as $\mathrm{Al}^{3+}$ and $\mathrm{In}^{3+}$, improve the sensing properties of $\mathrm{ZnO}[15,16]$. According to literature data, these group-III elements into the $\mathrm{ZnO}$ nanostructures act as singly charged donors and supply excess carriers to the conductance band, which will increase the conductance and provide a route to improve the sensing properties of $\mathrm{ZnO}$ [17].

In this study, AZO and IZO nanomaterials were synthesized, characterized and tested in the monitoring of low concentration of $\mathrm{CO}$ in air. The monitoring of $\mathrm{CO}$ is of utmost importance in the environmental control. $\mathrm{CO}$ is a gas produced during incomplete combustion and it is toxic at very low concentrations. In confined environments, such as automotive cabin, garage parking or tunnels, high concentrations of this pollutant can create serious hazard for the health and should be continuously monitored and controlled [18]. The concentrations of CO pollutant to be monitored in these ambient are very low, 5-50 ppm [19].

The responses of pure, Al- and In-doped $\mathrm{ZnO}$ sensing materials to $\mathrm{CO}$ were then examined and compared. Finally, the key factors affecting the sensing performances were studied and discussed here.

\section{Experimental Section}

\subsection{Samples Preparation}

AZO and IZO nanoparticles were prepared as previously reported by a sol-gel route using $16 \mathrm{~g}$ of zinc acetate dehydrate $\left[\mathrm{Zn}\left(\mathrm{CH}_{3} \mathrm{COO}\right)_{2} \cdot 2 \mathrm{H}_{2} \mathrm{O} ; 99 \%\right.$ ] as a precursor in $112 \mathrm{~mL}$ of methanol [20-22]. After $10 \mathrm{~min}$ of magnetic stirring at room temperature, an adequate quantity of aluminum nitrate-9-hydrate corresponding to $[\mathrm{Al}] /[\mathrm{Zn}]$ ratios of 0.03 were added to obtain $\mathrm{AZO}$ sample and an adequate quantity of indium chloride $\left(\mathrm{InCl}_{3}\right)$ corresponding to $[\mathrm{In}] /[\mathrm{Zn}]$ ratios of 0.02 were added to obtain IZO sample. $\mathrm{XRF}$ analysis of the samples showed a good agreement, within the experimental error, with the above nominal content. After 15 min under magnetic stirring, the solution was placed in an autoclave and 
dried in the supercritical conditions of ethyl alcohol $\left(\mathrm{T}_{\mathrm{c}}=243{ }^{\circ} \mathrm{C} ; \mathrm{P}_{\mathrm{c}}=63.6\right.$ bar $)$ according to protocol reported in the reference [23]. The prepared samples have been then annealed at $400{ }^{\circ} \mathrm{C}$ in air for $2 \mathrm{~h}$.

\subsection{Characterization}

The microstructure of the samples was investigated by XRD (Bruker AXS D8 Advance) using the $\mathrm{Cu} \mathrm{K} \alpha 1$ wavelength of $1.5405 \AA$ A. The crystallite size, D, was calculated by using the Scherrer's formula [24]:

$$
\mathrm{D}=\frac{0.9 \lambda}{\mathrm{B} \cos \theta_{\mathrm{B}}}
$$

where $\lambda$ is the $\mathrm{X}$-ray wavelength, $\theta_{\mathrm{B}}$ is Bragg diffraction angle and $\mathrm{B}$ is the full width at half maximum (FWHM) of the XRD peak.

The morphology of the sample particles was monitored by means of transmission electron microscopy (TEM) tests carried out with a JEM-200CX electron microscope.

\subsection{Sensing Test}

Sensors were made by printing films (1-10 $\mu \mathrm{m}$ thick) of the nano-powders dispersed in water on alumina substrates $(6 \mathrm{~mm} \times 3 \mathrm{~mm})$ with Pt interdigitated electrodes and Pt heater located on the backside. The sensors were then introduced in a stainless steel test chamber for the sensing tests. Electrical measurements were carried out in the temperature range from $\mathrm{RT}$ to $400{ }^{\circ} \mathrm{C}$, under a synthetic dry air total stream of $100 \mathrm{sccm}$, collecting the sensors resistance data in the four point mode. Gases coming from certified bottles can be further diluted in air at a given concentration by mass flow controllers. The concentration of $\mathrm{CO}$ target gas was varied from 5 to $50 \mathrm{ppm}$. A multimeter data acquisition unit Agilent 34970A was used for this purpose, while a dual-channel power supplier instrument Agilent E3632A was employed to bias the built-in heater of the sensor to perform measurements at super-ambient temperatures. The gas response, $S$, is defined as $S=R_{0} / R$ where $R_{0}$ is the baseline resistance in dry synthetic air $\left(20 \% \mathrm{O}_{2}\right.$ in nitrogen) and $\mathrm{R}$ is the electrical resistance of the sensor at different $\mathrm{CO}$ concentrations in dry synthetic air.

\section{Results and Discussion}

\subsection{Samples Characterization}

X-ray powder diffraction analysis was carried out to investigate the crystal structures of the pure and doped samples. Figure 1a shows the X-ray diffraction (XRD) pattern of as-prepared samples. Diffraction patterns show peaks corresponding to (002), (100), (102), (110) and (101) planes, which indicate that the samples are polycrystallines. All the diffraction peaks match the $\mathrm{ZnO}$ hexagonal wurtzite structure [25]. In IZO spectrum, peaks of other secondary phases $\left(\mathrm{Zn}_{2} \mathrm{In}_{2} \mathrm{O}_{3}\right.$ and $\left.\mathrm{In}_{2} \mathrm{O}_{3}\right)$ are very weak [26]. XRD pattern of AZO nanoparticles shows the presence of a peak associated to a $\mathrm{Zn}$ spinel phase, that is $\mathrm{ZnAl}_{2} \mathrm{O}_{4}$ [27]. It appears that, for the Al-doped $\mathrm{ZnO}$ sample, the (100) peak position is shifted at higher $2 \theta$-degree with respect to the (100) peak of pure $\mathrm{ZnO}$ and IZO sample. This is in according with the smaller ionic radius of $\mathrm{Al}^{3+}(0.057 \mathrm{~nm})$ with respect that of $\mathrm{Zn}^{2+}$ ion 
$(0.074 \mathrm{~nm})$ that leads to a reduction in the interlayer spacing of $\mathrm{ZnO}$ along the c-axis. The ionic radius of $\mathrm{In}^{3+}(0.081 \mathrm{~nm})$ is slightly larger than that of $\mathrm{Zn}^{2+}$, and seems do not modify substantially the $\mathrm{ZnO}$ lattice.

XRD on samples annealed at $400{ }^{\circ} \mathrm{C}$ confirms the presence of wurtzite structure. Interestingly, it can be seen in Figure 1b that the diffraction peaks of both annealed AZO and IZO samples are slightly shifted towards the lower Bragg angle as compared to pure $\mathrm{ZnO}$ sample. The peak shift may be attributed to the lattice expansion induced by annealing that leads to an increase in the interlayer spacing of doped- $\mathrm{ZnO}$ along the c-axis.

Figure 1. (a) X-ray diffraction spectra of as-prepared pure and doped $\mathrm{ZnO}$ aerogel nanoparticles. (b) Shift detail of (002) and (101) peaks of the samples treated at $400{ }^{\circ} \mathrm{C}$.

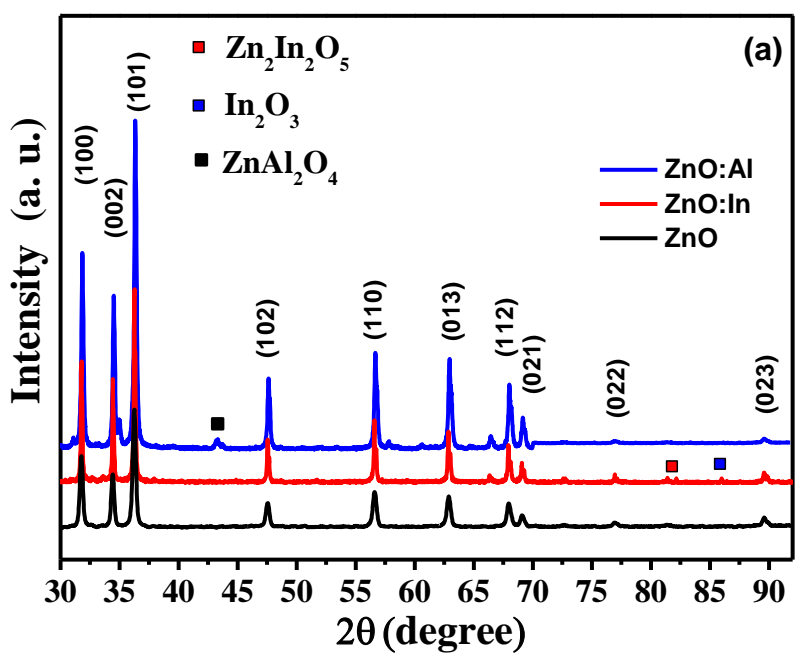

(a)

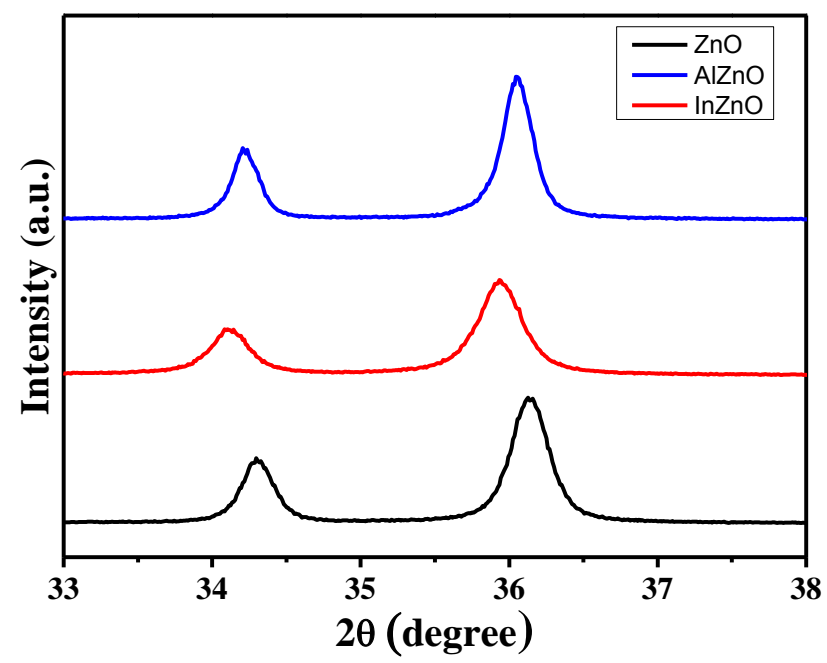

(b)

From the XRD measurements, the average crystallite size D, estimated by Scherrer's formula, were $65 \mathrm{~nm}$ for pure $\mathrm{ZnO}, 88 \mathrm{~nm}$ for AZO and $58 \mathrm{~nm}$ for IZO. The theoretical surface area, SA, was calculated using the equation $\mathrm{SA}=6 /\left(\mathrm{D}^{*} \rho\right)$, where $\mathrm{D}$ is the particle size, $\rho$ is the theoretical density of $\mathrm{ZnO}\left(5.606 \mathrm{~g} / \mathrm{cm}^{3}\right)$. Values of SA calculated are $16.5,12.2$ and $18.5 \mathrm{~m}^{2} / \mathrm{g}$ for $\mathrm{ZnO}, \mathrm{AZO}$ and IZO, respectively.

Figure 2 reports a typical TEM image taken from the as-prepared samples by sol-gel method and subsequent drying in supercritical conditions. Very small particles having size in the nanometer range are observed. The crystallites present a prismatic-like shape with a narrow particle size distribution. The majority of $\mathrm{ZnO}$ particles have a size of about 25-30 nm (Figure 2a). Doped samples show a similar prismatic shape [28]. However, TEM measurements show that the size of the majority of IZO particles varies between 40 and $50 \mathrm{~nm}$ [28], whereas the size of AZO particles varies between 20 and $50 \mathrm{~nm}$ (Figure 2b). TEM analysis on samples annealed at $400{ }^{\circ} \mathrm{C}$ showed that the shape of particles was not modified with respect to as prepared samples, and only an increase of the particle size of $\mathrm{ZnO}$ has been noted, which confirms XRD data. 
Figure 2. Typical TEM images showing the shape and size of as prepared aerogel nanoparticles. (a) $\mathrm{ZnO}$, (b) AZO.
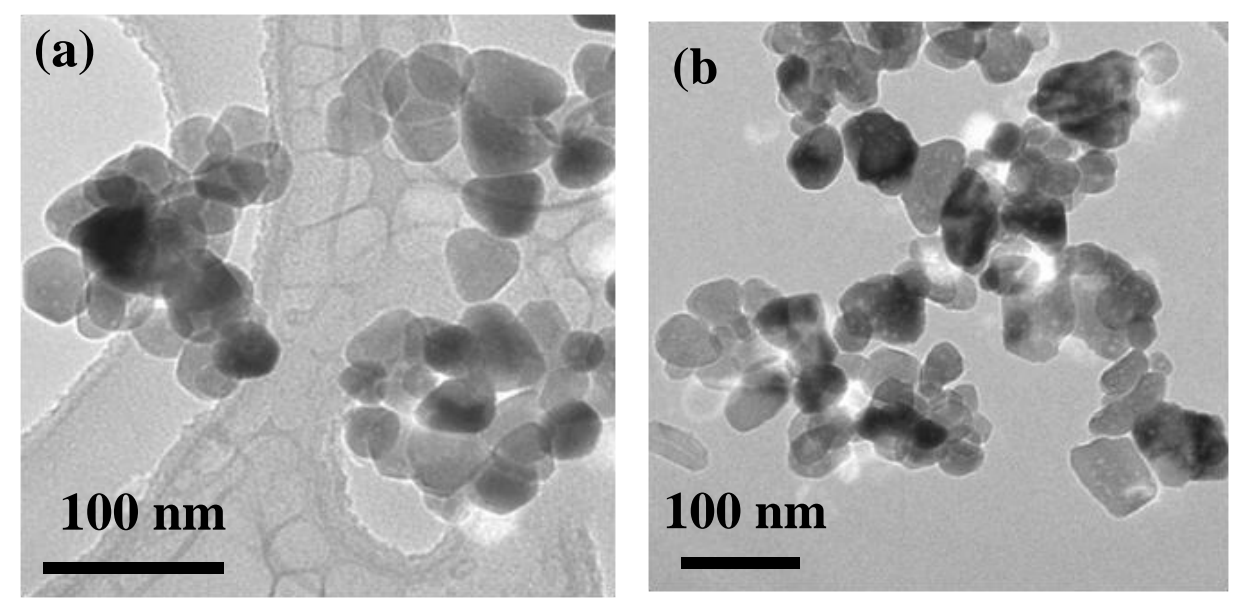

\subsection{Sensing Tests}

Sensing tests were carried out by means of a home-made sensing probe consisting of an alumina substrate with Pt interdigitated electrodes. On the back side of alumina substrate, a Pt heater provides to the heating of the sensing element. The active sensing layer was deposited on the Pt interdigitated electrodes area from an aqueous paste (in the weight ratio 1:1) of the samples by screen printing. No binder was necessary to enhance the adhesion of the sensing layer on the alumina substrate. After deposition the film was allowed to dry to room temperature and then annealed at $400{ }^{\circ} \mathrm{C}$ in air.

Figure 3 summarizes the data obtained, reporting the sensors response to $50 \mathrm{ppm}$ of $\mathrm{CO}$ versus the operating temperature. The pure $\mathrm{ZnO}$ shows a maximum at $250{ }^{\circ} \mathrm{C}$. For doped $\mathrm{ZnO}$, it appears clear that doping favors strongly the sensitivity towards carbon monoxide.

Figure 3. $\mathrm{CO}$ response of pure and doped $\mathrm{ZnO}$ nanoparticles as a function of the temperature.

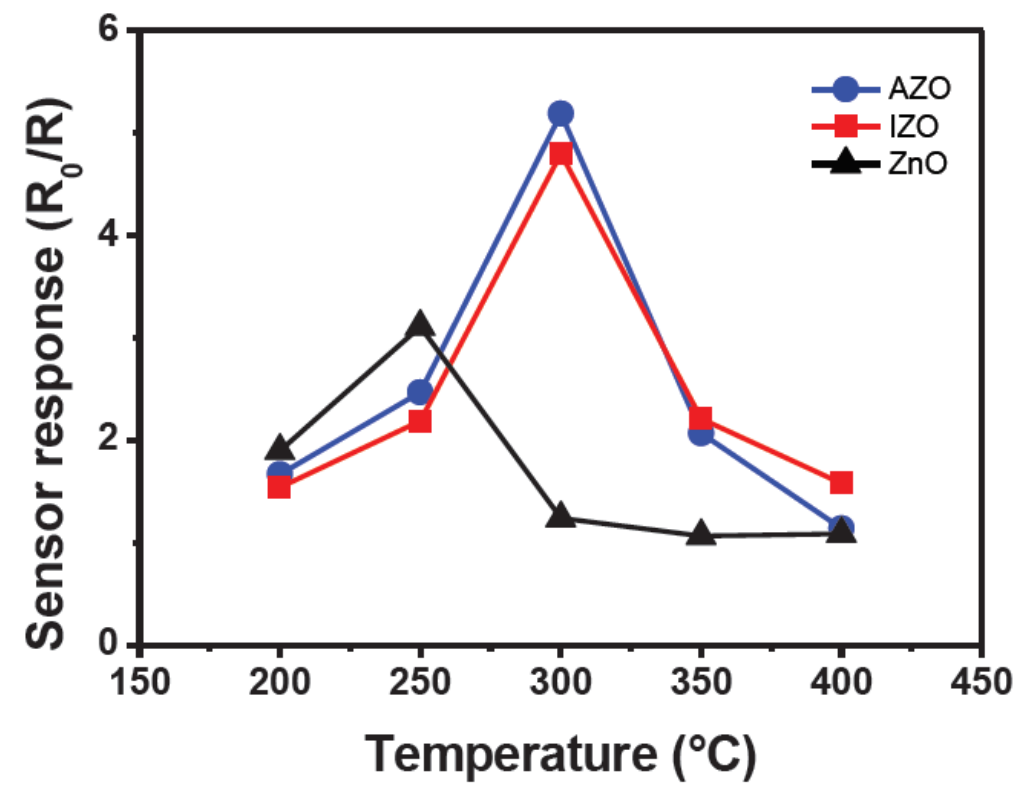


It appears that the sensor response is much dependent on the operating temperatures and the presence of additives. At lower temperature, the increase of the temperature leads an enhancement of sensor response. The responses show a maximum around $300{ }^{\circ} \mathrm{C}$ and AZO response is higher than IZO response. At higher temperature, the sensor response gets decreases. Temperature dependence of the sensing properties could result from change of the adsorption and desorption rates of the oxygen ions on the metal-oxide surface. It is well accepted that the sensitivity of semiconductor gas sensors is attributed to the chemisorption of oxygen on the oxide surface and the subsequent reaction between adsorbed oxygen and tested gas, which causes the resistance change. The same mechanism may be applied for the $\mathrm{CO}$ sensing of the present AZO and IZO layers. Thus, more CO molecules can react with more oxygen species on the layer grain surface, and can cause the decrease of barrier height leading to the reduction of electrical resistance. Stable oxygen ions species were $\mathrm{O}_{2}{ }^{-}$below $100{ }^{\circ} \mathrm{C}, \mathrm{O}^{-}$ between 100 and $300{ }^{\circ} \mathrm{C}$, and $\mathrm{O}^{2-}$ above $300{ }^{\circ} \mathrm{C}$ [29].

The relevant reactions on the surface area could be as follows:

$$
\begin{gathered}
2 \mathrm{CO}+\mathrm{O}_{2}^{-} \rightarrow 2 \mathrm{CO}_{2}+\mathrm{e}^{-} \\
\mathrm{CO}+\mathrm{O}^{-} \rightarrow \mathrm{CO}_{2}+\mathrm{e}^{-} \\
\mathrm{CO}+\mathrm{O}^{2-} \rightarrow \mathrm{CO}_{2}+2 \mathrm{e}^{-}
\end{gathered}
$$

Reducing agents such as $\mathrm{CO}$ will react rapidly with $\mathrm{O}^{-}$presents on the surface, but very slowly with $\mathrm{O}_{2}^{-}$. At temperature below $200{ }^{\circ} \mathrm{C}$, only Equation (2) plays a major role. As a result, a low $\mathrm{CO}$ response was achieved at that temperature. At $300{ }^{\circ} \mathrm{C}$, the dominant oxygen species adsorbed on the surface and grain boundaries of the AZO and IZO layers may be $\mathrm{O}^{-}$and $\mathrm{O}^{2-}$ (Equations (3) and (4)). For the gas sensing test performed at temperatures higher than $300{ }^{\circ} \mathrm{C}$, the surface reaction can be represented mainly by Equation (4).

Figure 4 shows the typical transient response of AZO and IZO layers at the operating temperature of $300{ }^{\circ} \mathrm{C}$. It was found that the injection of $50 \mathrm{ppm} \mathrm{CO}$ induced a remarkable decrease in electrical resistance of the layer, leading to response magnitude of 4.80 and 5.2 for IZO and AZO sensors, respectively. A similar behavior but with low response is also observed for pure $\mathrm{ZnO}$ sample. It is also noted from this figure that the signal could return to its initial value after several cycles. This indicates that the adsorption of $\mathrm{CO}$ on the layer surface was reversible. The $\mathrm{CO}$ adsorbed on the surface was surely desorbed when $\mathrm{CO}$ gas was pumped out. Figure $4 \mathrm{~d}$ shows transient response recovery for all samples at $5 \mathrm{ppm}$ CO. The sensor responses and recovery time are about $20 \mathrm{~s}$ respectively.

Figure 5 reports the response of the fabricated sensors, tested at different $\mathrm{CO}$ concentrations and at the operating temperature of $300{ }^{\circ} \mathrm{C}$. Both $\mathrm{Al}$ and In dopants lead to an enhancement of the sensors' response towards $\mathrm{CO}$ gas. Sensors response found to be obviously changed upon exposure to $\mathrm{CO}$ of as low as $5 \mathrm{ppm}$. At higher $\mathrm{CO}$ concentrations, the response was much increased. 
Figure 4. Transient responses of the sensors tested to different $\mathrm{CO}$ concentrations in air at the operating temperature of $300{ }^{\circ} \mathrm{C}$. (a) $\mathrm{AZO}$; (b) $\mathrm{IZO}$; (c) $\mathrm{ZnO}$; (d) Dynamic response comparison.

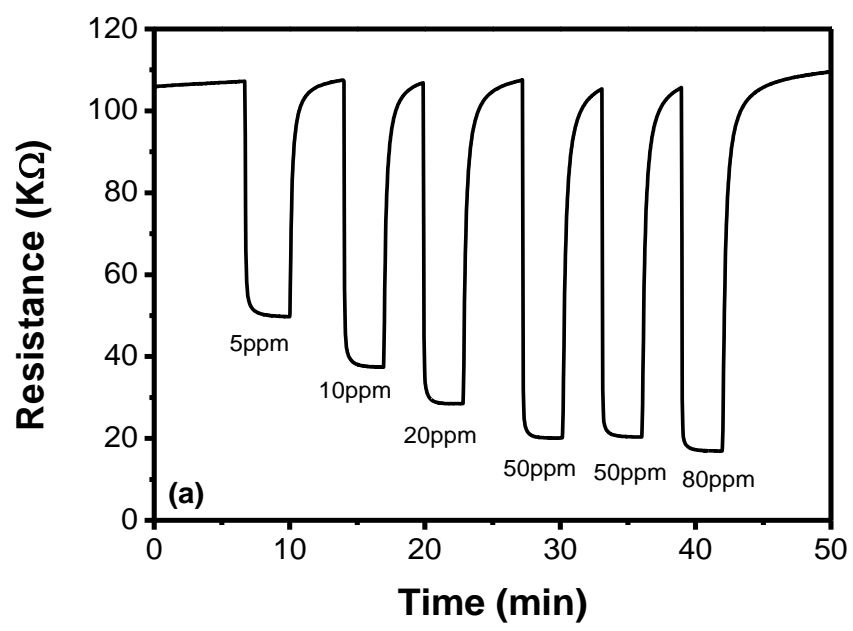

(a)

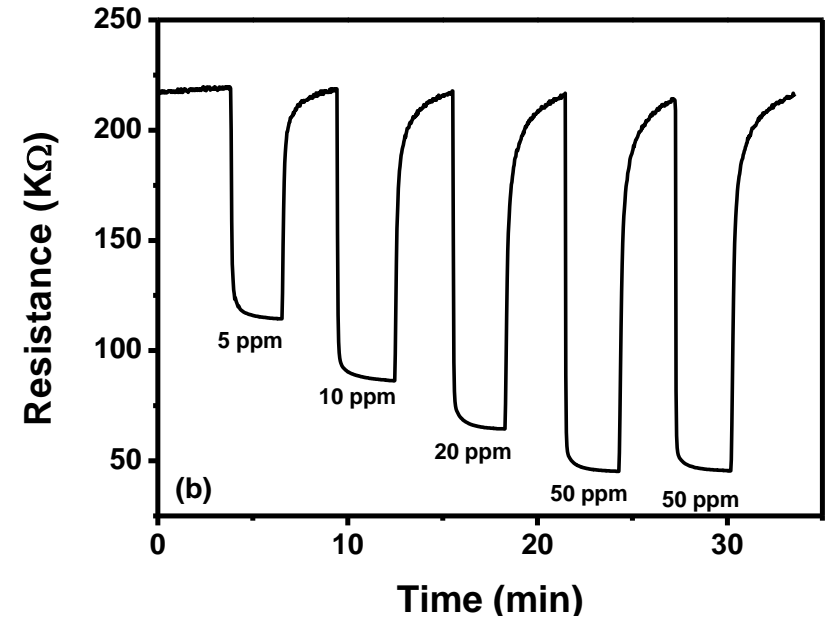

(c)

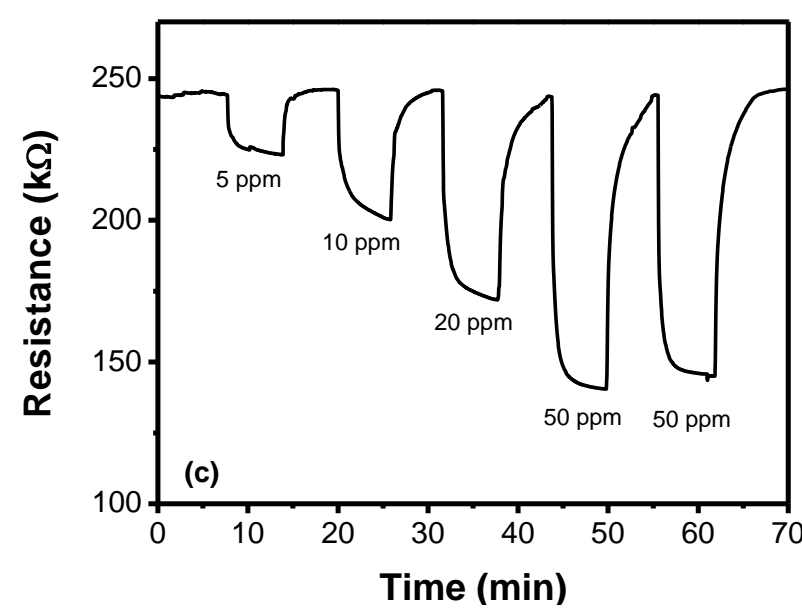

(b)

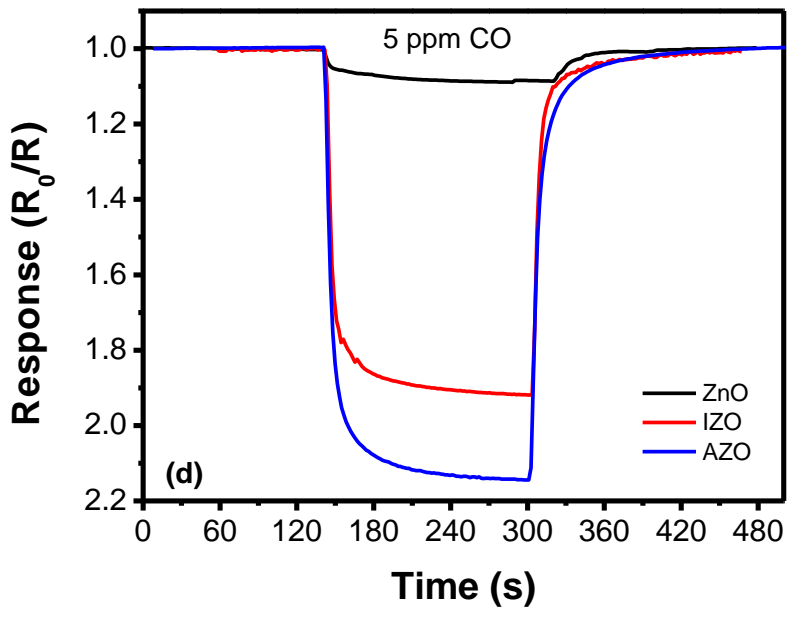

(d)

Figure 5. $\mathrm{CO}$ response of pure and doped $\mathrm{ZnO}$ nanoparticles as a function of $\mathrm{CO}$ concentrations.

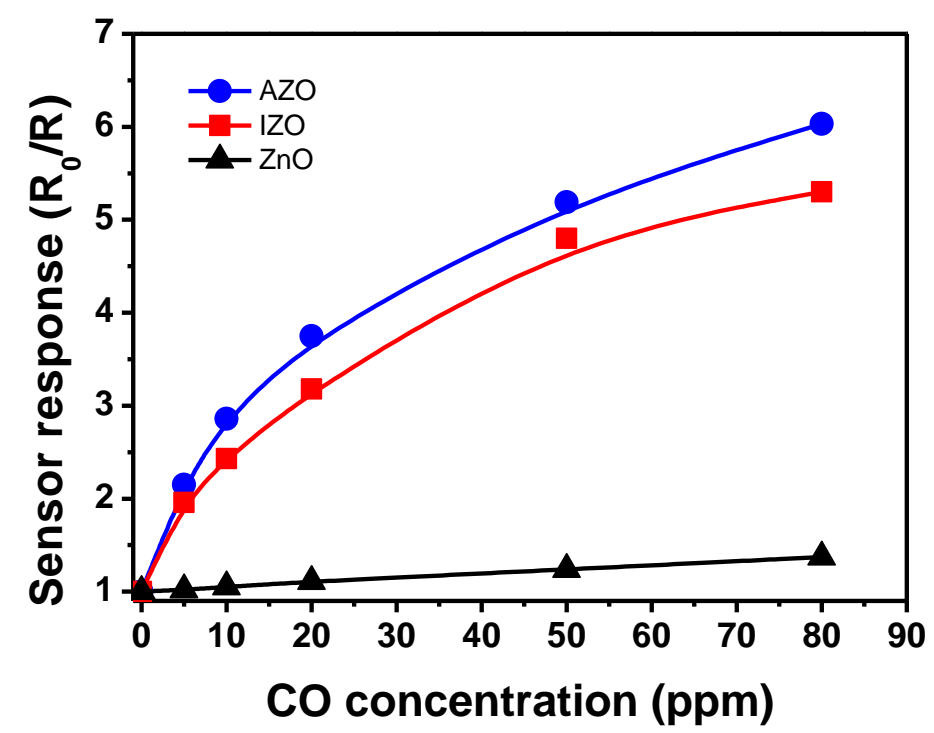


From characterization data of annealed samples, only a little change in the particle size has been evidenced for the annealed doped samples in comparison to pure $\mathrm{ZnO}$ sample. Then, it can be excluded that the sensing performances are due to a higher surface area of the doped samples. Instead, the strong improvement in the response to $\mathrm{CO}$ by $\mathrm{Al}$ and In doping can be attributed to changes to the defect equilibrium in the $\mathrm{ZnO}$ crystals by the substitution of $\mathrm{Al}^{3+}$ and $\mathrm{In}^{3+}$ for $\mathrm{Zn}^{2+}$ ions in the $\mathrm{ZnO}$ lattice. Oxygen vacancies are the most common defects in semiconductor metal oxides. $\mathrm{Zn}^{2+}$ ions in the $\mathrm{ZnO}$ lattice are easily substituted by $\mathrm{Al}^{3+}$ ions because the ionic radius of $\mathrm{Al}^{3+}(0.057 \mathrm{~nm})$ is smaller than that of $\mathrm{Zn}^{2+}$ ions $(0.074 \mathrm{~nm})$. However, to maintain electrical neutrality the positive valence charge of the substituted $\mathrm{Zn}$ site has to be compensated by releasing electrons. Thus, electrons are introduced into the doped $\mathrm{ZnO}$ samples, which increase the concentration of free electrons, resulting in the decrease in resistance of the oxide. Al doping can modify the surface state, such as by increasing the oxygen vacancies, leading to an enhancement of the gas sensing. Similar considerations can be made for indium doped Zinc oxide. Replacement of the $\mathrm{Zn}^{2+}$ cation by the $\mathrm{In}^{3+}$, which acts as donor, reduces the resistivity than pure zinc oxide. Further, indium doping leads to formation of active adsorption sites (indium atoms and oxygen vacancies) which favor the adsorption of oxygen species [30]. Thus, we can draw a conclusion that the defects play an important role in the sensing performance of AZO and IZO sensors.

However, in order to make any meaningful comparison between AZO and IZO and correlate the increase of sensor response to the presence of $\mathrm{Al}$ and In in the samples, a quantitative analysis of the surface dopant concentration should be made. As the surface composition could be different from bulk composition, a detailed XPS is planned, finalized to provide helpful indications about surface characteristics of the sensing layer films.

\section{Conclusions}

In summary, the morphological, microstructural and electrical properties of $\mathrm{Al}$ and In-doped $\mathrm{ZnO}$ particles prepared by a sol gel method were investigated. The sensing characteristics of chemoresistive sensors prepared were also investigated. The sensors fabricated based on Al-doped ZnO nanoparticles exhibited high sensitivity and very fast response and recovery times. Similar behavior was observed for In-doped $\mathrm{ZnO}$. Our results indicate that the $\mathrm{Al}$-doped $\mathrm{ZnO}$ and $\mathrm{In}$-doped $\mathrm{ZnO}$ sensors have potential applications in fabricating practical gas sensor devices.

\section{Author Contributions}

All authors contributed to this work. Mokhtar Hjiri prepared the samples and wrote the main paper. Gianluca Leonardi built the experimental setup and performed the experiments. Lassaad El Mir supervised the project and edited the manuscript. All authors contributed to the data analysis.

\section{Conflicts of Interest}

The authors declare no conflict of interest. 


\section{References}

1. Chopra, K.L.; Major, S.; Pandya, D.K. Transparent conductors-A status review. Thin Solid Films 1983, 102, 1-46.

2. Horrillo, M.C.; Gutie'rrez, J.; Are's, L.; Robla, J.I.; Sayago, I.; Getino, J. The influence of the tin-oxide deposition technique on the sensitivity to CO. Sens. Actuators B 1995, 25, 507-511.

3. Sberveglieri, G. Recent development in semiconducting thin film gas sensors. Sens. Actuators $B$ 1995, 23, 103-109.

4. Jones, A.; Jones, T.A.; Mann, B.; Firth, J.G. The effect of physical from the oxide on the conductivity changes produced by $\mathrm{CH}_{4}, \mathrm{CO}$ and $\mathrm{H}_{2} \mathrm{O}$ on ZnO. Sens. Actuators 1984, 5, 75-88.

5. Kohl, D. Surface processes in the detection of reducing gases with $\mathrm{SnO}_{2}$-based devices. Sens. Actuators 1989, 18, 71-113.

6. Seiyama, T.; Kato, A.; Fjiishi, K.; Nagatani, M. A New Detector for Gaseous Components Using Semiconductive Thin Films. Anal. Chem. 1962, 34, 1502-1503.

7. Basu, S.; Dutta, A. Modified heterojunction based on zinc oxide thin film for hydrogen gas-sensor application. Sens. Actuators B 1994, 22, 83-87.

8. Sberveglieri, G.; Nelli, P.; Groppelli, S.; Quaranta, F.; Valentini, A.; Vasanelli, L. Oxygen gas sensing characteristics at ambient pressure of undoped and lithium-doped $\mathrm{ZnO}$ sputtered thin filmd. Mater. Sci. Eng. B 1990, 7, 63-68.

9. Lampe, U.; Müller, J. Thin-film oxygen sensors made of reactively sputtered $\mathrm{ZnO}$. Sens. Actuators 1989, 18, 269-284.

10. Traversa, E.; Bearzotti, A. A novel humidity-detection mechanism for $\mathrm{ZnO}$ dense pellets. Sens. Actuators B 1995, 23, 181-186.

11. Hjiri, M.; El Mir, L.; Leonardi, S.G.; Donato, N.; Neri, G. CO and $\mathrm{NO}_{2}$ Selective Monitoring by ZnO-Based Sensors. J. Nanomater. 2013, 3, 357-369.

12. Baratto, C.; Sberveglieri, G.; Onischuk, A.; Caruso, B.; di Stasio, S. Low temperature selective $\mathrm{NO}_{2}$ sensors by nanostructured fibres of ZnO. Sens. Actuators B 2004, 100, 261-265.

13. Xu, J.; Shun, Y.; Pan, Q.; Qin, J. Sensing characteristics of double layer film of $\mathrm{ZnO}$. Sens. Actuators B 2000, 66, 161-163.

14. Yamazoe, N. Approaches for improving semiconductor gas sensor. Sens. Actuators B 1991, 5, 7-19.

15. Hou, Y.; Soleimanpour, A.M.; Jayatissa, A.H. Low resistive aluminum doped nanocrystalline zinc oxide for reducing gas sensor application via sol-gel process. Sens. Actuators B 2013, 177, 761-769.

16. Paraguay, D.F.; Miki-Yoshida, M.; Morales, J.; Solis, J.; Estrada, L.W. Influence of Al, In, Cu, Fe and $\mathrm{Sn}$ dopants on the response of thin film $\mathrm{ZnO}$ gas sensor to ethanol vapour. Thin Solid Films 2000, 373, 137-140.

17. Han, N.; Tian, Y.J.; Wu, X.F.; Chen, Y.F. Improving humidity selectivity in formaldehyde gas sensing by a two-sensor array made of Ga-doped ZnO. Sens. Actuators B 2009, 138, 228-235.

18. Neri, G.; Bonavita, A.; Micali, G.; Rizzo, G.; Callone, E.; Carturan, G. Resistive CO gas sensors based on $\mathrm{In}_{2} \mathrm{O}_{3}$ and $\mathrm{InSnO}_{\mathrm{x}}$ nanopowders synthesized via starch-aided sol-gel process for automotive applications. Sens. Actuators B 2008, 132, 224-233.

19. Galatsis, K.; Wlodarski, W. Car cabin air quality sensors and systems. Encycl. Sens. 2006, 8, 1-11. 
20. El Mir, L.; Amlouk, A.; Barthou, C.; Alaya, S. Synthesis and luminescence properties of $\mathrm{ZnO} / \mathrm{Zn} 2 \mathrm{SiO} 4 / \mathrm{SiO} 2$ composite based on nanosized zinc oxide-confined silica aerogels. Phys. $B$ 2007, 388, 412-417.

21. El Mir, L.; El Ghoul, J.; Alaya, S.; Ben Salem, M.; Barthou, C.; von Bardeleben, H.J. Synthesis and luminescence properties of vanadium-doped nanosized zinc oxide aerogel. Phys. B 2008, 403, 1770-1774.

22. El Mir, L.; Amlouk, A.; Barthou, C. Visible luminescence of $\mathrm{Al}_{2} \mathrm{O}_{3}$ nanoparticles embedded in silica glass host matrix. J. Phys. Chem. Solids 2006, 67, 2395-2399.

23. El Mir, L.; Ben Ayadi, Z.; Saadoun, M.; von Bardeleben, H.J.; Djessas, K.; Zeinert, A. Optical, electrical and magnetic properties of transparent, n-type conductive $\mathrm{Zn}_{0.90-\mathrm{x}} \mathrm{V}_{0.10} \mathrm{Al}_{\mathrm{x}} \mathrm{O}$ thin films elaborated from aerogel nanopowder. Phys. Stat. Sol. (a) 2007, 204, 3266-3277.

24. Cullity, B.D. Elements of X-ray Diffraction; Addison-Wesley: Reading, MA, USA, 1978; p. 102.

25. Wienke, J.; van der Zanden, B.; Tijssen, M.; Zeman, M. Performance of spray-deposited ZnO:In layers as front electrodes in thin-film silicon solar cells. J. Sol. Energy Mater. Sol. Cells 2008, 92, $884-890$

26. Singla, M.L.; Shafeeq, M.M.; Kumar, M. Optical characterization of ZnO nanoparticles capped with various surfactants. J. Lumin. 2009, 129, 434-438.

27. Ben Ayadi, Z.; El Mir, L.; Djessas, K.; Alaya, S. Effect of the annealing temperature on transparency and conductivity of ZnO:Al thin films. Thin Solid Films 2009, 517, 6305-6309.

28. El-Hilo, M.; Dakhel, A.A. Structural and magnetic properties of Mn-doped ZnO powders. $J$. Magn. Magn. Mater. 2011, 323, 2202-2205.

29. Gong, H.; Hu, J.Q.; Wang, J.H.; Ong, C.H.; Zhu, F.R. Nano-crystalline Cu-doped ZnO thin film gas sensor for CO. Sens. Actuators B 2006, 115, 247-251.

30. Ferro, R.; Rodríguez, J.A.; Bertrand, P. Peculiarities of nitrogen dioxide detection with sprayed undoped and indium-doped zinc oxide thin films. Thin Solid Films 2008, 516, 2225-2230.

(C) 2014 by the authors; licensee MDPI, Basel, Switzerland. This article is an open access article distributed under the terms and conditions of the Creative Commons Attribution license (http://creativecommons.org/licenses/by/3.0/). 